\title{
Predictors and prognosticators for survival with Yttrium-90 radioembolization therapy for unresectable colorectal cancer liver metastasis
}

\author{
Meaghan S. Dendy ${ }^{1,2}$, Johannes M. Ludwig² and Hyun S. Kim²,3 \\ ${ }^{1}$ Drexel University College of Medicine, Philadelphia, PA, USA \\ 2 Department of Radiology and Biomedical Imaging, Division of Interventional Radiology, Yale School of Medicine, New \\ Haven, CT, USA \\ ${ }^{3}$ Yale Cancer Center, Yale University, New Haven, CT, USA \\ Correspondence to: Hyun S. Kim, email: kevin.kim@yale.edu
}

Keywords: colorectal cancer, liver cancer, radioembolization, Y90, biomarkers

Received: December 28, $2016 \quad$ Accepted: February 27, $2017 \quad$ Published: March 08, 2017

Copyright: Dendy et al. This is an open-access article distributed under the terms of the Creative Commons Attribution License (CC-BY), which permits unrestricted use, distribution, and reproduction in any medium, provided the original author and source are credited.

\section{ABSTRACT}

This critical review aims to explore predictive and prognostic biomarkers of Yttrium-90 $\left(Y^{90}\right)$ radioembolization therapy of colorectal liver metastases. A brief overview of established predictive and prognostic molecular and genetic biomarkers in colorectal cancer therapies will be discussed. A review of the literature on imaging modalities, genetic, metabolic and other molecular markers and the subsequent outcomes in post- $\mathrm{Y}^{90}$ treatment will be presented. How these biomarkers and future biomarker research can inform locoregional treatment decisions in the clinical setting of metastatic colorectal cancer lesions of the liver will be explored. There are opportunities for personalized cancer treatment in the setting of $Y^{90}$ radioembolization. The ability to predict tumor response after Ytrium-90 radioembolization therapy can greatly impact clinical decision making and enhance treatment outcomes, therefore further research into the field is needed.

\section{INTRODUCTION}

Colorectal cancer $(\mathrm{CRC})$ is the second most common cause of cancer-related death in both men and women [1]. At time of diagnosis around $20 \%$ of patients present with distant metastases, while up to $60 \%$ will develop distant metastases during the course of disease $[2,3]$. The prognosis of patients with metastatic CRC (mCRC) is estimated to be only $11.7 \%$ within the first 5 years of diagnosis[1]. The liver is the most common site of metastases and liver involvement is thought to cause the majority of deaths in patients with metastatic CRC $[4,5]$.

The role of radioembolization in the treatment of CRLM

Surgical liver resection is the standard treatment for CRC metastases of the liver. However, only an estimated $20-30 \%$ are deemed curatively resectable $[6,7]$. Neoadjuvant chemotherapy has been shown to downstage
$10-30 \%$ of patients to allow for subsequent resection [8, 9]. Fluropyrimidine 5-fluorouracil has been in use for the past few decades while newer agents like oxaliplatin, irinotecan and inhibitors of VEGF and EGFR have been increasingly used with improved median survivals of more than 2 years [10-12]. There remains a vital need for treatment options in those cases that are considered unresectable and are also refractory to chemotherapy. Locoregional therapies have been developed in the past two decades and are evolving as primary treatment options in the process of downstaging disease to allow for curative resection. Y-90 radioembolization has shown promising results as a tool in the management of unresectable CRC liver metastases.

Y-90 radioembolization has been recommended for chemorefractory CRC patients who have primarily liver metastases and in those patients who wish to avoid systemic chemotherapy treatment [13]. Ideal candidates for radioembolization should be at least 18 years old with ECOG scores of $\leq 2$, serum bilirubin $<3.0 \mathrm{mg} / \mathrm{dL}$, 
Table 1a: Imaging Predictors

\begin{tabular}{|c|c|c|c|}
\hline Study & Study Design & Number of Subjects & Outcome \\
\hline $\begin{array}{l}\text { Jiao et al. and Szyszko et } \\
\text { al. (2007) }\end{array}$ & retrospective & 10 patients & PET better than CT at assessing response \\
\hline Flamen et al. (2008) & prospective & 8 patients (39 liver lesions) & $\begin{array}{l}\text { cut-off value of } 1 \text { for the MAA-tumor-to-normal uptake ratio } \\
\text { estimates a favorable outcome }\end{array}$ \\
\hline Dudeck et al. (2010) & prospective & 21 patients (41 lesions) & ADC decreased significantly in responding lesions \\
\hline Tochetto et al. (2010) & retrospective & 28 patients ( 74 lesions) & $\begin{array}{l}\text { decreased attenuation on CT correlates with PET-FDG uptake } \\
\text { and anticipates treatment success }\end{array}$ \\
\hline Gulec et al. (2010) & prospective & 20 patients & $\begin{array}{l}\text { favorable outcomes: pre-treatment FTV }<200 \mathrm{cc}, \mathrm{TLG}<600 \mathrm{~g} \text {; } \\
\text { post-treatment FTV }>30 \mathrm{cc}, \text { TLG of }<100 \mathrm{~g}\end{array}$ \\
\hline Zerizer et al. (2012) & retrospective & 25 patients (121 lesions) & $\begin{array}{l}\text { PET/CT correlates with the responses of biomarkers (LDH, } \\
\text { CEA, CA 19-9) }\end{array}$ \\
\hline Fendler et al. (2013) & prospective & 80 patients & responders with change in TLG had longer survival \\
\hline Lam et al. (2013) & retrospective & 25 patients & $\begin{array}{l}\text { SPECT-based calculation of DT correlated with radiographic } \\
\text { response, decrease in serum CEA, and OS }\end{array}$ \\
\hline Soydal et al. (2013) & prospective & 35 patients & $\Delta \mathrm{TLG}>26.5$ showed increased survival \\
\hline Ulrich et al. (2013) & retrospective & 66 patients (435 lesions) & $\begin{array}{l}\text { no association of response with }(99 \mathrm{~m}) \mathrm{Tc}-\mathrm{MAA} \text { uptake or with } \\
\text { catheter position }\end{array}$ \\
\hline Kennedy et al. (2015) & retrospective & 195 patients & RECIST 1.0 responders showed increased survival \\
\hline Sabet et al. (2015) & retrospective & 51 patients & $\begin{array}{l}\text { increased OS via PET response; Hepatic tumor burden }>25 \% \\
\text { showed decreased survival }\end{array}$ \\
\hline Fowler et al. (2015) & prospective & 9 patients & increased dose (avg of $29.8 \mathrm{~Gy}$ ) anticipated response \\
\hline Barabasch et al. (2015)* & prospective & 20 patients & $\begin{array}{l}\text { sensitivity for detecting response was significantly higher for } \\
\text { MRI than for PET }\end{array}$ \\
\hline Chapiro et al. (2015) & retrospective & 29 patients & $\begin{array}{l}\text { EASL and mRECIST did not predict patient survival; qEASL } \\
\text { was sole predictor of patient survival }\end{array}$ \\
\hline Schmeel et al. (2016) & retrospective & 44 patients & ADC changes on DWI can predict survival \\
\hline
\end{tabular}

*- study was conducted on mCRC patients as well as other liver malignancies

granulocyte count $>1.5 \times 10^{9}$, serum creatinine $<2.0 \mathrm{mg} /$ dl, platelet count $>50 \times 10^{9}$, and have adequate pulmonary function $[14,15]$. There have been some encouraging studies that have shown good response in salvage patients. One study by Kennedy et al. demonstrated median OS of 10.5 months in treatment responders, compared to that of non-responders $(4.5$ months $(p=0.0001))$ [16]. Hendlisz et al. conducted a prospective, randomized phase III trial showing that radioembolization combined with chemotherapy lengthens the time-to-progression in CRLM after having progressed on initial systemic treatment. Time to progression was 4.5 months when combined with Y-90 treatment, as compared to 2.1 months in the cohort that only received chemotherapy ( $p=0.03$ ) [17]. Despite the many studies supporting its safety and low rate of toxicity, the NCCN guidelines for treatment of metastatic colorectal cancer lacks consensus amongst panel members and it currently remains a Category 3 treatment [18]. Further prospective randomized clinical trials are required before Y-90 radioembolization can be definitely established as primary treatment option.

Selection of optimal patients for Y-90 treatment is key, as it is vital in interventional oncology to allow for the best possible patients outcomes and also to lower health care costs by avoiding unbeneficial therapies. Patient selection parameters currently in use have not been optimized and have lead to possible over- and under-treatment using these therapies. As such, there is an opportunity in this area to enhance patient selection and patient outcomes by identifying biomarkers that will better guide treatment decisions.

\section{The role of biomarkers for the treatment of mCRC with ${ }^{90}$ Y-radioembolization}

The National Institutes of Health define Biomarkers as "a characteristic that is objectively measured and evaluated as an indicator of normal biological processes, pathogenic processes, or pharmacologic responses to a therapeutic intervention"[19].

Research has shown that a number of biomarkers can predict survival outcomes in patients with metastatic CRC. Genetic markers as well as metabolic and imaging markers have been shown to be predictive of tumor growth and metastatic spread. In a clinical setting the use of these markers can lead to important treatment decisions in regards to which lesions might be more susceptible to 
Table 1b: Molecular and Genetic Predictors

\begin{tabular}{|l|l|l|l|}
\hline Study & Study Design & Number of Subjects & Outcome \\
\hline Gray et al. (1989) & retrospective & 10 patients & $\begin{array}{l}\text { patients who received }>30 \text { Gy had at lease a 50\% decrease in serum } \\
\text { CEA }\end{array}$ \\
\hline Boppudi et al. (2006) & retrospective & 54 patients & CEA levels decrease faster than decrease in lesion size via CT \\
\hline Fahmueller et al. (2012) & prospective & 49 patients & $\begin{array}{l}\text { increased CEA, CA 19-9, CYFRA 21-1, CRP, LDH, AST, CHE, GGT, } \\
\text { alk phos, amylase and nucleosomes suggest poor outcomes after Y-90 }\end{array}$ \\
\hline Fahmueller et al. (2013 & prospective & 49 patients & high HMGB1 were associated with poor outcome \\
\hline Melucci et al. (2013) & prospective & 50 patients & $\begin{array}{l}\text { reduction of survivin, p53, and Bcl-2 expression post-Y90 suggest a } \\
\text { favorable outcome }\end{array}$ \\
\hline Carpizo et al. (2014) & prospective & 22 patients & $\begin{array}{l}\text { poor outcomes: increased baseline Ang-2 and IL-8; transient increases } \\
\text { in VEGF and PDGF-BB post-Y-90 }\end{array}$ \\
\hline Tohme et al. (2015) & retrospective & 104 patients & decreased survival of patients with high NLR \\
\hline Henrie et al. (2015) & retrospective & 12 patients & increased albumin associated with increased OS \\
\hline Lahti et al. (2015) & retrospective & 104 patients & KRAS wt patients have increased survival advantage \\
\hline Magnetta et al. (2016) & retrospective & 82 patients & PFS was longer in KRAS wt patients \\
\hline
\end{tabular}

specific treatments to improve patient care. The purpose of this review is to summarize and discuss the current literature behind biomarkers of $\mathrm{CRC}$, including metabolic, genetic, tumor and imaging markers that have been tested and evaluated for Y-90 radioembolization to better inform interventional oncologist on treatment decisions and spark interest in this research field.

\section{Predictive biomarkers of Ytrium-90 (Y90) radioembolization therapy in metastatic CRC}

\section{Molecular and genetic biomarkers}

Limited information exists on biomarkers of CRC patients with liver metastases who undergo radioembolization treatment. The first molecular biomarker study completed in this population was a retrospective study by Gray et al. in $1989(n=10)$. The group explained that patients who received $>30$ Gy had at least a $50 \%$ decrease in serum carcinoembryonic antigen (CEA)[20]. Though this was only completed in a small 10 patient cohort and the study was done via laparoscopic surgery, it was an early demonstration as to how biomarkers can guide our understanding of treatment success. More recently, Boppudi et al. $(n=54)$ found that CEA levels fell rapidly $(>75 \%)$ within 2 months of selective internal radiation therapy (SIRT) and found it to be more reliable in determining treatment response than CT scanning completed soon after treatment of mCRC liver lesions. The data showed that it took 3-21 months (median 12 months) for tumor size to maximally decrease post-treatment [21]. The group theorized that CEA levels are more representative of tumor response than imaging is due to the destroyed microvasculature of the tumor post-radioembolization treatment. This destruction leads to decreased efficiency of macrophage response and resulting cleanup. Another study, from Tohme et al. ( $n=$
104), has shown via univariate and multivariate analysis that elevated neutrophil-lymphocyte ratio (NLR) in preoperative patients receiving radioembolization for CRC liver metastases is associated with poor survival outcomes (median OS high NLR $=5.6 \mathrm{mos}$; low NLR $=10.6 \mathrm{mos}$ $(p=0.001))[22]$. The same group was able to show that patients with low neutrophil-lymphocyte ratio treated with radioembolization attained a survival advantage, which has been corroborated by other reports $[23,24]$. The science behind this is not yet fully understood, but is thought to be caused by the decreased lymphocytic response to tumor cells and the increased angiogenic factors released by neutrophils. Both these factors would give the tumor cells a survival advantage and would decrease the efficacy of radioembolization treatment. Fahmueller et al. $(n=49)$ completed a prospective study that showed CEA, CA 19-9, CYFRA 21-1, CRP, LDH, AST, choline esterase (CHE), gamma-glutamyl-transferase (GGT), alkaline phosphatase, and amylase (all $0 \mathrm{~h}, 24 \mathrm{~h}$ ) and nucleosomes $(24 \mathrm{~h})$ were found to be prognostic relevant markers $(p<$ .05 ) of survival in univariate analysis. In Cox-regression multivariate analysis the combination of CRP with AST was found to show the most significance with regards to survival implications. It should also be noted that these studies were all completed with blood samples as opposed to tumor biopsies [25]. Another study from the same group $(n=49)$ showed that high mobility group box 1 protein (HMGB1) levels at 24 hours post-treatment were higher in patients with disease progression as compared to those without progression of disease. Overall survival statistics showed that high pretherapeutic $(0 \mathrm{hr})$ and $24 \mathrm{hr}$ levels of HMGB1 were associated with poor outcomes (at 0hr: median OS 19.6, 15.4, 7.8, 4.6 in Quartiles 1-4, $p=.012$; at $24 \mathrm{hr}$ : median OS 6.8, 13.8, 4.8 in Quartiles 2-4, $p=$ .004) [26]. A prospective study completed by Melucci et al. $(n=50)$ with biopsy samples found that survivin $(92.3 \%$ vs $53.8 \%$; $p=0.06)$, p53 $(100 \%$ vs $69.2 \%$; $p=$ $0.05)$ and $\mathrm{Bcl}-2(69.2 \%$ vs $53.8 \% ; p=0.05)$ expression 
Table 1c: Tumor and Patient Characteristics

\begin{tabular}{|l|l|l|l|}
\hline Study & Study Design & $\begin{array}{l}\text { Number of } \\
\text { Subjects }\end{array}$ & Outcome \\
\hline Dunfee et al. (2010)* & prospective & 130 patients* & $\begin{array}{l}\text { ECOG performance status }>0 \text {, hepatic tumor burden of 51\%- } \\
75 \% \text {, bilirubin level }>1.3 \text { mg/dL, response based on WHO } \\
\text { criteria, and lymphocyte depression yield worse outcomes }\end{array}$ \\
\hline Deipolyi et al. (2014) & retrospective & 62 patients & $\begin{array}{l}\text { higher LSF had significantly decreased survival; pts who } \\
\text { received chemotherapy before Y90 had low LSF had the } \\
\text { longest survival }\end{array}$ \\
\hline Schonewolf et al. (2014) & retrospective & 30 patients & $\begin{array}{l}\text { tumor volumes }<300 \text { mL were predictive for extrahepatic } \\
\text { failure patterns }\end{array}$ \\
\hline Tohme et al. (2014); HPB & retrospective & 107 patients & $\begin{array}{l}\text { no significant difference was found with regard to age, } \\
\text { presence of extrahepatic disease at time of Y90 was } \\
\text { associated worse survival }\end{array}$ \\
\hline Sofocleous et al. (2015) & prospective & 53 patients & $\begin{array}{l}\text { CEA levels } \geq 90 \text { ng/mL and microscopic lymphovascular } \\
\text { invasion of the primary were predictors of decreased OS }\end{array}$ \\
\hline Abbott et al. (2015) & retrospective & 68 patients & OS for patients with $\leq 25 \%$ HBD was better \\
\hline Fendler et al. (2015) & retrospective & 100 patients & $\begin{array}{l}\text { reduced patient survival: no liver surgery before Y90), CEA } \\
\text { upper limit of normal, and summed CT size of the largest two } \\
\text { liver lesions } \geq 10 \text { cm }\end{array}$ \\
\hline Xing et al. (2016) & retrospective & 79 patients & $\begin{array}{l}\text { high LSF demonstrated poorer survival compared with low } \\
\text { LSF }\end{array}$ \\
\hline
\end{tabular}

*- study was conducted on mCRC patients as well as other liver malignancies

decreases after radioembolization treatment and may inform radiosensitivity of CRC liver metastases [27]. The group postulated that the change in these biomarkers post-Y-90 treatment might be due to epigenetic changes or clonal selection. Another small prospective study was completed by Carpizo et al. $(n=22)$ and showed Ang-2 $(p=.033)$ and IL-8 $(p=.041)$ both had higher baseline levels in patients with decreased overall survival (OS) ( $<6$ months). Patients with OS $\leq 6$ months were found to have transient increased levels of VEGF and PDGFBB post-Y90 therapy compared to patients with OS > 6 months after treatment indicating their possible use as prognostic biomarkers post-treatment [28]. These findings support the concept that radioembolization treatment may enhance angiogenesis signaling and the possible utility in pretreating patients receiving Y-90 therapy with antiangiogenic therapies. Henrie et al. ( $n$ $=12$ ) then showed increased albumin was found to be significantly associated with increased OS for $\mathrm{mCRC}$ after radioembolization treatment $(p=0.02, \mathrm{HR}=0.02,95 \%$ CI: 0.001-0.52.) [29].

The first genetic mutation study in this patient population was completed by Lahti et al. $(n=104)$, who showed that unresectable CRC liver metastases with wild type KRAS show greater response to Y-90 radioembolization than those lesions with mutant KRAS. Lahti et al. showed that median OS from first Y-90 radioembolization was significantly greater in KRAS wt patients (9.5 mo vs $4.8 \mathrm{mo} ; p=.041)$ [30]. This was corroborated in a recent study by Magnetta et al. $(n=82)$, which showed PFS was longer in KRAS wt (median 166 days [95\% CI 96-258 days]) vs. mut (median 91 days [95\% CI 79-104 days], $p=0.002$ ). The study also showed that KRAS mut patients were 1.48 times more likely to progress at first follow-up imaging than wt $(95 \%$ CI $1.06-$ $2.08, p=0.024)$ [31]. This correlation may be due to the ability of KRAS mut tumors to metastasize more readily or also could be due to resistance to radiation-induced apoptosis present in these tumor cells [30].

\section{Imaging markers}

Other forms of predictors are needed to form better therapeutic strategies where radioembolization of CRC liver metastases is concerned. There is ample research available in support of imaging studies being used soon after Y-90 radioembolization to inform a more accurate assessment of tumor response. Jiao et al. and Szyszko et al. $(n=10)$ reported on the use of PET scan response being more successful in measuring tumor response than CT scans. The data showed that the PET scan mean pretreatment SUV was $12.2+/-3.7$ as compared to the posttreatment SUV of $9.3+/-3.7$. Only $13 \%$ of the same tumors had reduced in size on CT after Y-90 treatment [32, 33]. The presence of necrosis, hemorrhage and cystic changes on CT makes measurements difficult in the immediate post-treatment setting, whereas the change in SUV values can be seen earlier and assessed more accurately [34]. Tochetto et al. $(n=28)$ then revealed that post-treatment attenuation correlates with metabolic activity on PETFDG and can be used to anticipate treatment success. The lesions treated in this study had decreased diameter, 
Table 2: Pre- and Post-Treatment Biomarkers

\begin{tabular}{|c|c|}
\hline Pre-Treatment & Post-Treatment \\
\hline \multicolumn{2}{|c|}{ Imaging } \\
\hline \multicolumn{2}{|c|}{ Good outcome } \\
\hline cut-off value of 1 for MAA-tumor-to-normal uptake ratio & PET scan response (decreased SUV) \\
\hline FTV $<200$ cc & ADC decrease on DWI \\
\hline TLG $<600 \mathrm{~g}$ & CT response (decreased diameter, volume, attenuation) \\
\hline \multirow[t]{6}{*}{ sufficient Y-90 dose to tumor } & FTV $<30 \mathrm{cc}$ \\
\hline & TLG $<100 \mathrm{~g}$ \\
\hline & $\Delta T L G>26.5$ \\
\hline & response via RECIST 1.0 \\
\hline & MRI response \\
\hline & response via qEASL \\
\hline \multicolumn{2}{|c|}{ Molecular and Genetic } \\
\hline \multicolumn{2}{|c|}{ Good outcome } \\
\hline increased albumin & decreased survivin, $\mathrm{p} 53, \mathrm{Bcl}-2$ expression \\
\hline \multicolumn{2}{|c|}{ Poor outcome } \\
\hline increased HMGB1 levels & increased HMGB1 levels \\
\hline increased NLR & increased levels of nucleosomes \\
\hline increased Ang-2 and IL-8 & transient increase in VEGF an PDGF-BB \\
\hline KRAS mut & $\begin{array}{l}\text { increased levels of CEA, CA 19-9, CYFRA 21-1, LDH, AST, choline } \\
\text { esterase, GGT, alk phos, amylase }\end{array}$ \\
\hline \multicolumn{2}{|l|}{$\begin{array}{l}\text { increased levels of CEA, CA 19-9, CYFRA 21-1, LDH, AST, choline } \\
\text { esterase, GGT, alk phos, amylase }\end{array}$} \\
\hline \multicolumn{2}{|c|}{$\begin{array}{ll} & \text { Tumor and Patient Characteristics } \\
\end{array}$} \\
\hline \multicolumn{2}{|c|}{ Good outcome } \\
\hline \multicolumn{2}{|l|}{ low \% liver replacement/ hepatic tumor burden } \\
\hline \multicolumn{2}{|l|}{ low ECOG score } \\
\hline \multicolumn{2}{|c|}{ Poor outcome } \\
\hline \multicolumn{2}{|l|}{ extrahepatic disease } \\
\hline \multicolumn{2}{|l|}{ increased bilirubin (>1.3) } \\
\hline \multicolumn{2}{|l|}{ lymphocyte depression } \\
\hline \multicolumn{2}{|l|}{ high LSF } \\
\hline \multicolumn{2}{|l|}{ no liver resection prior to $\mathrm{Y} 90$} \\
\hline \multicolumn{2}{|l|}{ summed CT size of largest 2 liver lesions $>10 \mathrm{~cm}$} \\
\hline microscopic lymphovascular invasion of the primary tumo & \\
\hline
\end{tabular}

volume, and attenuation posttreatment via CT $(p<.05)$. Percent change in attenuation had higher correlation with percent change in SUV $(r=0.61)$ than diameter $(r$ $=0.39)$ or volume $(r=0.49)$ when compared, and that $\geq 15 \%$ decreased attenuation showed $84.2 \%$ sensitivity and $83.3 \%$ specificity in predicting response at FDG-PET evaluation [35]. Zerizer et al. $(n=25)$ used a retrospective model to look at the superiority of F-FDG PET/CT and its correlation with the responses of tumor markers after Y-90 treatment. The study results showed that PET/CT is superior in response assessment to RECIST or tumor density measurements [36]. Fendler et al. $(n=80)$ also found that using RECIST criteria did not predict survival but also correlated the PET response to survival. The responders with change in metabolic volume or total lesion glyscolysis (TLG) were shown to survive longer (92 vs. $49 \mathrm{wk}(p=0.006)$ and $91 \mathrm{vs.} 48 \mathrm{wk}(p=0.025))$ [37]. Another study by Sabet et al. $(n=51)$ supported this by showing early metabolic responders survived longer than non-responders $(p<0.001)$ with a median OS of 10 months (95\% CI 3-16) versus 4 months (95\% CI
2-6). Sabet et al. also divulged that hepatic tumor burden impacted treatment outcome $(p<0.001)$ with a median OS of 5 months ( $95 \%$ CI, 3-7) for patients $>25 \%$ metastatic liver replacement compared to 14 months (95\% CI 6-22) for the less advanced patients [38]. The study by Soydal et al. $(n=35)$ again corroborates the association between PET response and survival showing that a change in TLG $>26.5$ yielded longer survival $(20.76+/-2.71(95 \% \mathrm{CI}$ 15.46-26.06) mos) compared to a change in TLG $<26.5$ $(11.32+/-1.18(95 \%$ CI 9.02-13.62 mos $)(p=0.016)$ [39]. A large retrospective study by Kennedy et al. ( $n=$ 195) seems to counter the argument that RECIST cannot anticipate survival as it showed responders survived longer in an analysis according to RECIST 1.0: (PR median (95\% CI) 25.2 (range, 9.2-49.4) months vs. SD 15.8 (range, 9.3-21.1) months vs. PD 7.1 (range, 6.0-9.5) months ( $p$ $<0.0001$ ) [40]. In considering response criteria, Chapiro et al. $(n=29)$ then reported that EASL and mRECIST could not reliably predict patient survival $(p=0.27$ and $p=0.44$, respectively). Their uni- and multivariate analysis demonstrated that the quantitative European 
Association for the Study of the Liver (qEASL) response assessment criteria was identified as the sole predictor of patient survival (9.9 months for responders, 6.9 months for non-responders; $p=0.038$; HR 0.4) [41]. The existing data on which imaging tool is most effective in assessing tumor response to Y-90 treatment has been shown to be controversial, but it is clear that many opportunities exist to establish a standard tool in the field.

A study by Flamen et al. $(n=8)$ prospectively demonstrated that by using a cut-off value of 1 for the MAA-tumor-to-normal uptake ratio, a significant metabolic response could be predicted after Y-90 treatment $(\mathrm{sens}=89 \%, \mathrm{spec}=65 \%, \mathrm{PPV}=71 \%, \mathrm{NPV}=87 \%)$ [42]. This algorithm is based on the understanding that a relatively cold lesion on MAA-SPECT will be less responsive to radioembolization therapy. Lam et al. ( $n$ $=25$ ) then demonstrated SPECT-based calculation of dose to tumor (DT) (mean DT, 44.2 Gy) correlated with radiographic response $(p<0.001)$, decrease in serum CEA $(p<0.05)$, and OS $(p<0.01)$. The study showed that patients who received a DT $>55$ Gy had a median survival of $32.8 \mathrm{mo}$, compared with $7.2 \mathrm{mo}$ in patients who received less $(p<0.05)$ [43]. Using diffusion weighted imaging to predict therapeutic effects of SIRT,
Dudeck et al. $(n=21)$ showed the apparent diffusion coefficient (ADC) decreased significantly in responding lesions by $10.7+/-8.4 \%(p<0.0001)$ [44]. One other DWI study by Schmeel et al. $(n=44)$ presented data that ADC changes on DWI can predict survival in CRC after SIRT. Other parameters found that were associated with median OS were: optimal functional imaging response (18 vs. 5 mos; $p<0.001$ ), hepatic tumor burden $<50 \%$ (8 vs. 5 mos; $p=0.018$ ), ECOG performance scale $<1$ (10 vs. 4 mos; $p=0.012$ ) and progressive disease according to RECIST ( 8 vs. 3 mos; $p=0.001$ ) [45]. Gulec et al. ( $n=$ 20 ), in a prospective trial, demonstrated that pre- and posttreatment functional tumor volume (FTV) and total lesion glycolysis (TLG) were strongly associated with survival. The median survival of the pretreatment cohort with FTV $>200$ cc was 11.2 months, compared to the cohort with FTV $<200$ cc, whose median survival was $26.9 \operatorname{mos}(p<$ $0.05)$. The median survival of the cohort with pretreatment TLG values $>600 \mathrm{~g}$ was 11.2 months, as compared to the cohort with TLG $<600 \mathrm{~g}$ whose median survival was 26.9 $\operatorname{mos}(p<0.05)[46]$.

One study by Ulrich et al. $(n=66)$ demonstrated that response to Y-90 radioembolization was found to be independent of the degree of $(99 \mathrm{~m})$ Tc-MAA uptake

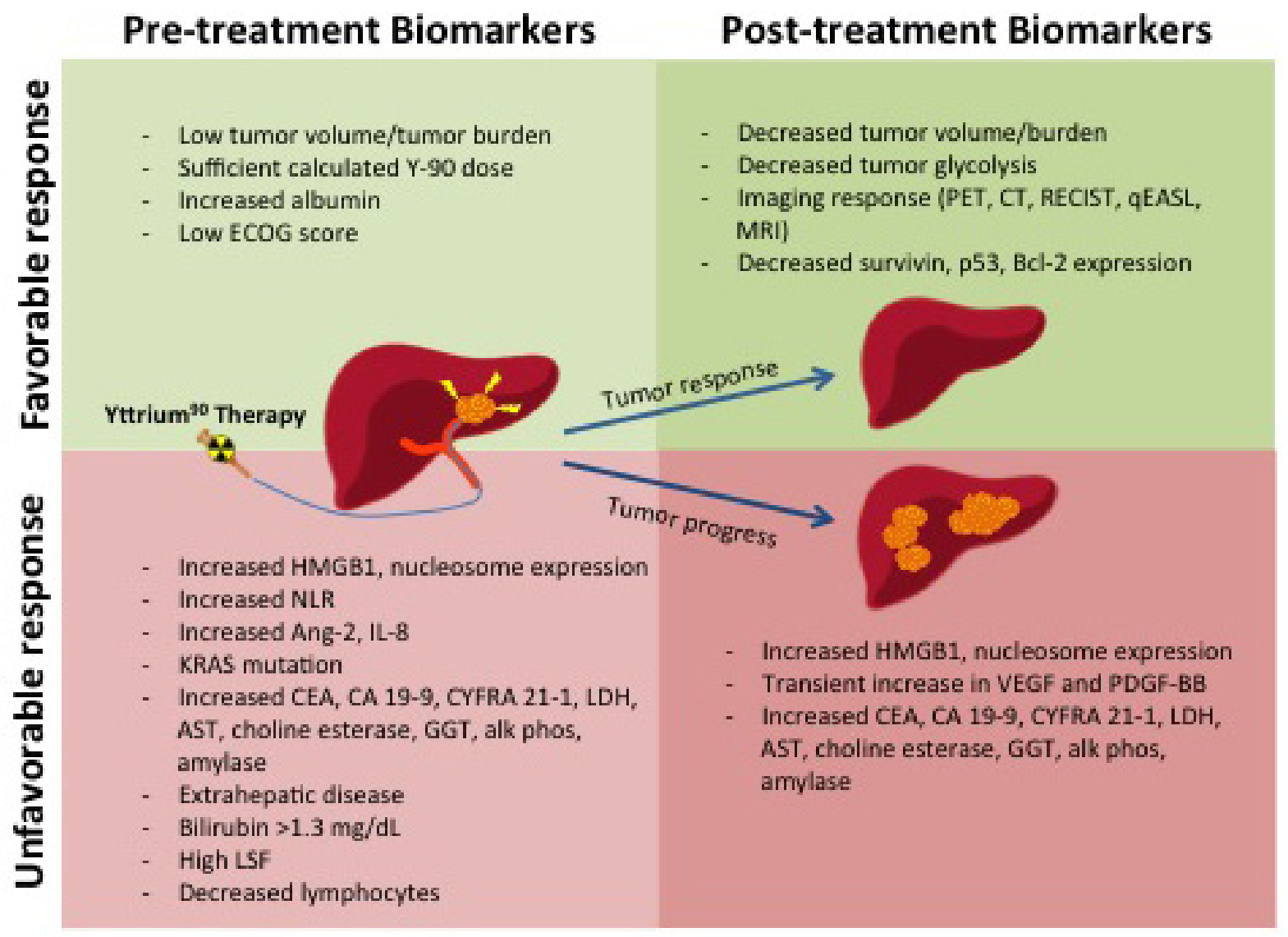

Figure 1: Pre-treatment Biomarkers and Post-treatment Biomarkers 
and that this should not preclude patients from treatment [47]. Fowler et al. $(n=9)$ looked at the use of PET/MRI dose volume histograms in relation to its ability to predict response. Their data revealed an average dose of 29.8 Gy offered $76.9 \%$ sensitivity and $75.9 \%$ specificity of tumor response [48]. Barabasch et al. $(n=20)$ compared diffusion-weighted MRI to PET/CT in determining early response to Y-90. The study found that the PPV was $96 \%$ for MRI and $88 \%$ for PET/CT and the NPV to predict absence was $92 \%$ for MRI and $56 \%$ for PET. The sensitivity for detecting response was significantly higher for MRI $(96 \%)$ than for PET $(65 \%)(p<0.02)$. However, it should be noted that only 20 of the 35 patients studied in this cohort had mCRC [49]. As the field of radiology is inherent to interventional oncology, imaging biomarker studies that consider response and survival are imperatively important to future treatment decisions. Further identification of which imaging modality would best assess treatment response post-Y-90 is still needed.

\section{Tumor and patient characteristic markers}

Some information has also been published on tumor and patient characteristics that can possibly predict tumor response to Y-90 radioembolization treatment in mCRC lesions of the liver. Xing et al. $(n=79)$ recently reported that high lung shunt fraction (LSF) demonstrated significantly poorer survival compared with low LSF in colorectal liver metastases treated with Y-90 (13.5 vs 7.0 months, $p=0.013$ ) [50]. This correlation is most likely due to increased vasculature development in advanced tumors and may also be due to decreased dosing as a result of increased LSF on pre-treatment assessments. Deipolyi et al. $(n=62)$ also looked at LSF and determined that patients with higher LSF had significantly decreased survival compared to patients with lower LSF ( $p=$ $.03)$. This study also showed that patients who received chemotherapy before radioembolization and had low LSF had the longest survival $(p=.02)$ [51]. Dunfee et al. ( $n=$ $130)$ reported that response seen on imaging 1 -month post Y-90 treatment can be a favorable indicator of prognosis. A significant effect on survival was found via multivariate analysis in regards to ECOG performance status $>0$ $(\mathrm{HR}=7.98 ; 95 \% \mathrm{CI}, 3.98-16)$, hepatic tumor burden of 51\%-75\% (HR, 2.46; 95\% CI, 1.01-6.02), bilirubin level $>1.3 \mathrm{mg} / \mathrm{dL}$ (HR, 2.60; 95\% CI, 1.27-5.34), response on imaging based on WHO criteria (HR, 0.48 ; 95\% CI, 0.240.94), and lymphocyte depression (HR, 0.56; 95\% CI, 0.31-0.96) [52]. A retrospective study from Schonewolf et al. $(n=30)$ demonstrated that smaller tumor volumes $(<300 \mathrm{~mL})$, were predictive for extrahepatic failure patterns compared with hepatic recurrence $(p=0.046)$ [53]. Tohme et al. $(n=107)$ then looked into age as a possible cause of difference in survival. In that study, no significant difference was found with regard to median OS between younger [8.4 months; 95\% confidence interval $(\mathrm{CI})=6.2-10.6]$ or elderly patients $(8.2$ months;
$95 \% \mathrm{CI}=5.9-10.5, p=0.667)$. As expected, presence of extrahepatic disease at time of Y-90 was associated with worse median survival in both age groups [54]. Abbott et al. $(n=68)$ looked into hepatic burden of disease (HBD) and showed median and 2-year OS for patients with $\leq 25 \%$ versus $>25 \%$ HBD were 19.6 months and $42 \%$ versus 3.4 months and $0 \%(p<.0001)$ [55]. Next, Fendler et al. ( $n$ $=100$ ) demonstrated that four specific parameters were associated with survival in patients with $\mathrm{mCRC}$ receiving Y-90. Reduced patient survival was found via multivariate analysis in the following cohorts: no liver surgery before SIRT (HR:1.81, $p=0.014$ ), CEA serum level $\geq 150 \mathrm{ng} / \mathrm{ml}$ (HR:2.08, $p=0.001$ ), transaminase toxicity level $\geq 2.5 \mathrm{x}$ upper limit of normal (HR:2.82, $p=0.001)$, and summed computed tomography (CT) size of the largest two liver lesions $\geq 10 \mathrm{~cm}$ (HR:2.31, $p<0.001$ ) [56]. Sofocleous et al. $(n=53)$ demonstrated via multivariate analysis that CEA levels greater than, or equal to $90 \mathrm{ng} / \mathrm{mL}(p=0.004)$ and microscopic lymphovascular invasion of the primary $(p=0.002)$ are independent predictors of decreased overall survival in patients undergoing Y-90 treatment of CRLM [57]. Understanding which tumor characteristics act as good parameters to use in patient selection is key to better quality patient care, patient outcomes and decreased treatment costs by avoiding unbeneficial procedures.

\section{Patient selection and future of predictive markers in metastatic CRC}

Clinical factors presented in this review have the potential to improve Y-90 patient selection. The most promising of which include known clinical prognostic factors: ECOG status, NLR, Albumin levels, LDH, and tumor burden.

It should be noted that very few "true" biomarkers have been identified to aid in the selection of CRLM patients for Y-90 treatment. True predictive markers such as KRAS and pre-treatment MAA-tumor-to-normal uptake ratio are excellent examples capable of informing Y-90 treatment outcomes. It is important then to identify other accepted CRC biomarkers in the literature to inform prospective research projects. The most commonly used serum biomarker in CRC treatment is CEA. CRC produces larger quantities of the CEA protein and it is thought to be involved in the primary tumor's ability to metastasize. [58] It has been shown to be most effective in assessing for recurrence and response to treatment and has also been shown to be highly sensitive for liver metastases. [58, 59] A number of heritable mutations have been shown to lead to CRC-related polyposis syndromes including mutations in APC, MUTYH, STK11, LKB1, SMAD4, BRMP1A and PTEN genes [60]. Lynch syndrome is the most common heritable form of CRC and has been shown to result from inherited mutations in mismatch repair genes (MMR). The four most commonly mutated MMR genes 
are MLH1, MSH2, MSH6 and PMS2 [61]. In addition to screening for heritable causes, MMR mutations leading to microsatellite instability have been shown to be a good prognostic indicator with patients having fewer metastases [62]. MMR positive patients have also been shown to respond better to immunotherapy with immune checkpoint inhibitors, presumably due to a higher immunogenicity of these tumors [63]. Research into targeted therapy has shown that specific genetic mutations impact tumor response to individual therapies. CRC tumors with mutations in KRAS and NRAS yield a decreased response to anti-EGFR therapy [64] [65]. Reduced overall survival and progression-free survival have been shown in CRC when the BRAF gene is mutated [66]. Loss of heterozygosity $(\mathrm{LOH})$ and chromosomal instability $(\mathrm{CIN})$, specifically $\mathrm{LOH}$ at $18 \mathrm{q}$, have been shown to cause a possible resistance to fluorouracil [67]. Other genes such as PTEN, ERCC1, VEGF, PIK3CA and Top I have been studied but have not shown to be predictive in response to specific therapies or have shown inconsistent research results $[68,69]$. A recent meta-analysis by Mei et al. specifically looked at PIK3CA and determined that there is a neutral association with PIK3CA mutation in $\mathrm{CRC}$ and patient survival. The data reported showed the summary HRs for OS and PFS were 0.96 (95\% CI 0.83 1.12 ) and 1.20 (95\% CI $0.98-1.46)$, for mut and wt cohorts respectively [70].

These biomarkers have mainly been studied in regards to standard systemic chemotherapy treatments. It is very possible that using these biomarkers, that have been established in a systemic therapy model, could allow for translational research in the field of locoregional therapies such as Y-90 radioembolization, to allow for better optimization of patient selection.

\section{CONCLUSIONS}

There have been strides made in the development of biomarkers that can inform interventionalists on treating mCRC lesions of the liver with Y90 radioembolization. There is still a great need for information, especially genetic tumor markers, that could predict which lesions would be most susceptible to treatment. Additional prospective, large cohort studies on genetic markers such as BRAF, MMR genes and NRAS would greatly benefit the field and help to inform treatment decisions.

\section{CONFLICTS OF INTEREST}

The authors of this manuscript have no potential conflicts of interest to report.

\section{REFERENCES}

1. Siegel RL, Miller KD, Jemal A. Cancer statistics, 2015. CA Cancer J Clin. 2015; 65: 5-29. doi: 10.3322/caac.21254.
2. Siegel R, DeSantis C, Virgo K, Stein K, Mariotto A, Smith T, Cooper D, Gansler T, Lerro C, Fedewa S, Lin C, Leach C, Cannady RS, et al. Cancer treatment and survivorship statistics, 2012. CA Cancer J Clin. 2012; 62: 220-41. doi: 10.3322/caac. 21149 .

3. Howlader N, Noone A, Krapcho M, Garshell J, Miller D, Altekruse SF, Kosary CL, Yu M, Ruhl J, Tatalovich Z, Mariotto A, Lewis DR, Chen HS, et al. (2015). SEER Cancer Statistics Review, 1975-2012, National Cancer Institute. (Bethesda, MD).

4. Donadon M, Ribero D, Morris-Stiff G, Abdalla EK, Vauthey JN. New paradigm in the management of liveronly metastases from colorectal cancer. Gastrointest Cancer Res. 2007; 1: 20-7. doi:

5. Abdalla EK, Adam R, Bilchik AJ, Jaeck D, Vauthey JN, Mahvi D. Improving resectability of hepatic colorectal metastases: expert consensus statement. Ann Surg Oncol. 2006; 13: 1271-80. doi: 10.1245/s10434-006-9045-5.

6. Garden OJ, Rees M, Poston GJ, Mirza D, Saunders M, Ledermann J, Primrose JN, Parks RW. Guidelines for resection of colorectal cancer liver metastases. Gut. 2006; 55 Suppl 3: iii1-8. doi: 10.1136/gut.2006.098053.

7. Pawlik TM, Choti MA. Surgical therapy for colorectal metastases to the liver. J Gastrointest Surg. 2007; 11: 105777. doi: 10.1007/s11605-006-0061-3.

8. Nordlinger B, Van Cutsem E, Rougier P, Kohne CH, Ychou M, Sobrero A, Adam R, Arvidsson D, Carrato A, Georgoulias V, Giuliante F, Glimelius B, Golling M, et al. Does chemotherapy prior to liver resection increase the potential for cure in patients with metastatic colorectal cancer? A report from the European Colorectal Metastases Treatment Group. Eur J Cancer. 2007; 43: 2037-45. doi: 10.1016/j.ejca.2007.07.017.

9. Adam R, Delvart V, Pascal G, Valeanu A, Castaing D, Azoulay D, Giacchetti S, Paule B, Kunstlinger F, Ghemard O, Levi F, Bismuth H. Rescue surgery for unresectable colorectal liver metastases downstaged by chemotherapy: a model to predict long-term survival. Ann Surg. 2004; 240: 644-57; discussion 57-8.

10. Simmonds PC. Palliative chemotherapy for advanced colorectal cancer: systematic review and meta-analysis. Colorectal Cancer Collaborative Group. Bmj. 2000; 321: 531-5.

11. Nordic Gastrointestinal Tumor Adjuvant Therapy Group. Expectancy or primary chemotherapy in patients with advanced asymptomatic colorectal cancer: a randomized trial. J Clin Oncol. 1992; 10: 904-11. doi: 10.1200/ jco.1992.10.6.904.

12. Scheithauer W, Rosen H, Kornek GV, Sebesta C, Depisch D. Randomised comparison of combination chemotherapy plus supportive care with supportive care alone in patients with metastatic colorectal cancer. Bmj. 1993; 306: 752-5.

13. Raval M, Bande D, Pillai AK, Blaszkowsky LS, Ganguli S, Beg MS, Kalva SP. Yttrium-90 radioembolization of 
hepatic metastases from colorectal cancer. Front Oncol. 2014; 4: 120. doi: 10.3389/fonc.2014.00120.

14. Wong CY, Salem R, Raman S, Gates VL, Dworkin HJ. Evaluating 90Y-glass microsphere treatment response of unresectable colorectal liver metastases by [18F]FDG PET: a comparison with CT or MRI. Eur J Nucl Med Mol Imaging. 2002; 29: 815-20. doi: 10.1007/s00259-002-07874 .

15. Wong CY, Salem R, Qing F, Wong KT, Barker D, Gates V, Lewandowski R, Hill EA, Dworkin HJ, Nagle C. Metabolic response after intraarterial $90 \mathrm{Y}$-glass microsphere treatment for colorectal liver metastases: comparison of quantitative and visual analyses by 18F-FDG PET. J Nucl Med. 2004; 45: 1892-7.

16. Kennedy AS, Coldwell D, Nutting C, Murthy R, Wertman DE Jr, Loehr SP, Overton C, Meranze S, Niedzwiecki J, Sailer S. Resin 90Y-microsphere brachytherapy for unresectable colorectal liver metastases: modern USA experience. Int J Radiat Oncol Biol Phys. 2006; 65: 412-25. doi: 10.1016/j.ijrobp.2005.12.051.

17. Hendlisz A, Van den Eynde M, Peeters M, Maleux G, Lambert B, Vannoote J, De Keukeleire K, Verslype C, Defreyne L, Van Cutsem E, Delatte P, Delaunoit T, Personeni N, et al. Phase III trial comparing protracted intravenous fluorouracil infusion alone or with yttrium-90 resin microspheres radioembolization for liver-limited metastatic colorectal cancer refractory to standard chemotherapy. J Clin Oncol. 2010; 28: 3687-94. doi: 10.1200/jco.2010.28.5643.

18. National Comprehensive Cancer Network. NCCN Clinical Practice Guidelines in Oncology: Colon Cancer. V.2.2016.

19. Strimbu K, Tavel JA. What are biomarkers? Curr Opin HIV AIDS. 2010; 5: 463-6. doi: 10.1097/ COH.0b013e32833ed177.

20. Gray BN, Burton MA, Kelleher DK, Anderson J, Klemp P. Selective internal radiation (SIR) therapy for treatment of liver metastases: measurement of response rate. J Surg Oncol. 1989; 42: 192-6.

21. Boppudi S, Wickremesekera SK, Nowitz M, Stubbs R. Evaluation of the role of CT in the assessment of response to selective internal radiation therapy in patients with colorectal liver metastases. Australas Radiol. 2006; 50: 5707. doi: 10.1111/j.1440-1673.2006.01630.x.

22. Tohme S, Sukato D, Chalhoub D, McDonald KA, Zajko A, Amesur N, Orons P, Marsh JW, Geller DA, Tsung A. Neutrophil-lymphocyte ratio is a simple and novel biomarker for prediction of survival after radioembolization for metastatic colorectal cancer. Ann Surg Oncol. 2015; 22: 1701-7. doi: 10.1245/s10434-014-4050-6.

23. Bester L, Meteling B, Pocock N, Pavlakis N, Chua TC, Saxena A, Morris DL. Radioembolization versus standard care of hepatic metastases: comparative retrospective cohort study of survival outcomes and adverse events in salvage patients. J Vasc Interv Radiol. 2012; 23: 96-105. doi: 10.1016/j.jvir.2011.09.028.
24. Seidensticker R, Denecke T, Kraus P, Seidensticker M, Mohnike K, Fahlke J, Kettner E, Hildebrandt B, Dudeck O, Pech M, Amthauer H, Ricke J. Matched-pair comparison of radioembolization plus best supportive care versus best supportive care alone for chemotherapy refractory liverdominant colorectal metastases. Cardiovasc Intervent Radiol. 2012; 35: 1066-73. doi: 10.1007/s00270-011-02347.

25. Fahmueller YN, Nagel D, Hoffmann RT, Tatsch K, Jakobs T, Stieber P, Holdenrieder S. Predictive and prognostic value of circulating nucleosomes and serum biomarkers in patients with metastasized colorectal cancer undergoing Selective Internal Radiation Therapy. BMC Cancer. 2012; 12: 5. doi: 10.1186/1471-2407-12-5.

26. Fahmueller YN, Nagel D, Hoffmann RT, Tatsch K, Jakobs $\mathrm{T}$, Stieber P, Holdenrieder S. Immunogenic cell death biomarkers HMGB1, RAGE, and DNAse indicate response to radioembolization therapy and prognosis in colorectal cancer patients. Int J Cancer. 2013; 132: 2349-58. doi: 10.1002/ijc. 27894.

27. Melucci E, Cosimelli M, Carpanese L, Pizzi G, Izzo F, Fiore F, Golfieri R, Giampalma E, Sperduti I, Ercolani C, Sciuto R, Mancini R, Garufi C, et al. Decrease of survivin, p53 and Bcl-2 expression in chemorefractory colorectal liver metastases may be predictive of radiosensivity radiosensivity after radioembolization with yttrium-90 resin microspheres. J Exp Clin Cancer Res. 2013; 32: 13. doi: 10.1186/1756-9966-32-13.

28. Carpizo DR, Gensure RH, Yu X, Gendel VM, Greene SJ, Moore DF, Jabbour SK, Nosher JL. Pilot study of angiogenic response to yttrium-90 radioembolization with resin microspheres. J Vasc Interv Radiol. 2014; 25: 297-306 e1. doi: 10.1016/j.jvir.2013.10.030.

29. Henrie AM, Wittstrom K, Delu A, Deming P. Evaluation of Liver Biomarkers as Prognostic Factors for Outcomes to Yttrium-90 Radioembolization of Primary and Secondary Liver Malignancies. Cancer Biother Radiopharm. 2015; 30 : 305-9. doi: 10.1089/cbr.2015.1842.

30. Lahti SJ, Xing M, Zhang D, Lee JJ, Magnetta MJ, Kim HS. KRAS Status as an Independent Prognostic Factor for Survival after Yttrium-90 Radioembolization Therapy for Unresectable Colorectal Cancer Liver Metastases. J Vasc Interv Radiol. 2015; 26: 1102-11. doi: 10.1016/j. jvir.2015.05.032.

31. Magnetta MJ, Ghodadra A, Lahti SJ, Xing M, Zhang D, Kim HS. Connecting cancer biology and clinical outcomes to imaging in KRAS mutant and wild-type colorectal cancer liver tumors following selective internal radiation therapy with yttrium-90. Abdominal Radiology. 2016: 1-9. doi: 10.1007/s00261-016-0875-8.

32. Jiao LR, Szyszko T, Al-Nahhas A, Tait P, Canelo R, Stamp G, Wasan H, Lowdell C, Philips R, Thillainayagam A, Bansi D, Rubello D, Limongelli P, et al. Clinical and imaging experience with yttrium-90 microspheres in the management of unresectable liver tumours. Eur J Surg 
Oncol. 2007; 33: 597-602. doi: 10.1016/j.ejso.2007.02.021.

33. Szyszko T, Al-Nahhas A, Canelo R, Habib N, Jiao L, Wasan H, Pagou M, Tait P. Assessment of response to treatment of unresectable liver tumours with $90 \mathrm{Y}$ microspheres: value of FDG PET versus computed tomography. Nucl Med Commun. 2007; 28: 15-20. doi: 10.1097/MNM.0b013e328011453b.

34. Bienert M, McCook B, Carr BI, Geller DA, Sheetz M, Tutor C, Amesur N, Avril N. 90Y microsphere treatment of unresectable liver metastases: changes in 18F-FDG uptake and tumour size on PET/CT. European Journal of Nuclear Medicine and Molecular Imaging. 2005; 32: 778-87. doi: 10.1007/s00259-004-1752-1.

35. Tochetto SM, Rezai P, Rezvani M, Nikolaidis P, Berggruen S, Atassi B, Salem R, Yaghmai V. Does multidetector $\mathrm{CT}$ attenuation change in colon cancer liver metastases treated with $90 \mathrm{Y}$ help predict metabolic activity at FDG PET? Radiology. 2010; 255: 164-72. doi: 10.1148/ radiol.09091028.

36. Zerizer I, Al-Nahhas A, Towey D, Tait P, Ariff B, Wasan H, Hatice G, Habib N, Barwick T. The role of early (1)(8) F-FDG PET/CT in prediction of progression-free survival after (9)(0)Y radioembolization: comparison with RECIST and tumour density criteria. Eur J Nucl Med Mol Imaging. 2012; 39: 1391-9. doi: 10.1007/s00259-012-2149-1.

37. Fendler WP, Philippe Tiega DB, Ilhan H, Paprottka PM, Heinemann V, Jakobs TF, Bartenstein P, Hacker M, Haug AR. Validation of several SUV-based parameters derived from 18F-FDG PET for prediction of survival after SIRT of hepatic metastases from colorectal cancer. J Nucl Med. 2013; 54: 1202-8. doi: 10.2967/jnumed.112.116426.

38. Sabet A, Meyer C, Aouf A, Sabet A, Ghamari S, Pieper CC, Mayer K, Biersack HJ, Ezziddin S. Early post-treatment FDG PET predicts survival after 90Y microsphere radioembolization in liver-dominant metastatic colorectal cancer. Eur J Nucl Med Mol Imaging. 2015; 42: 370-6. doi: 10.1007/s00259-014-2935-z.

39. Soydal C, Kucuk ON, Gecim EI, Bilgic S, Elhan AH. The prognostic value of quantitative parameters of $18 \mathrm{~F}-\mathrm{FDG}$ $\mathrm{PET} / \mathrm{CT}$ in the evaluation of response to internal radiation therapy with yttrium-90 in patients with liver metastases of colorectal cancer. Nucl Med Commun. 2013; 34: 501-6. doi: 10.1097/MNM.0b013e32835f9427.

40. Kennedy AS, Ball DS, Cohen SJ, Cohn M, Coldwell DM, Drooz A, Ehrenwald E, Kanani S, Nutting CW, Moeslein FM, Putnam SG 3rd, Rose SC, Savin MA, et al. Hepatic imaging response to radioembolization with yttrium-90labeled resin microspheres for tumor progression during systemic chemotherapy in patients with colorectal liver metastases. J Gastrointest Oncol. 2015; 6: 594-604. doi: 10.3978/j.issn.2078-6891.2015.082.

41. Chapiro J, Duran R, Lin M, Schernthaner R, Lesage D, Wang Z, Savic LJ, Geschwind JF. Early survival prediction after intra-arterial therapies: a $3 \mathrm{D}$ quantitative MRI assessment of tumour response after TACE or radioembolization of colorectal cancer metastases to the liver. Eur Radiol. 2015; 25: 1993-2003. doi: 10.1007/ s00330-015-3595-5.

42. Flamen P, Vanderlinden B, Delatte P, Ghanem G, Ameye L, Van Den Eynde M, Hendlisz A. Multimodality imaging can predict the metabolic response of unresectable colorectal liver metastases to radioembolization therapy with Yttrium-90 labeled resin microspheres. Phys Med Biol. 2008; 53: 6591-603. doi: 10.1088/0031-9155/53/22/019.

43. Lam MG, Goris ML, Iagaru AH, Mittra ES, Louie JD, Sze DY. Prognostic utility of $90 \mathrm{Y}$ radioembolization dosimetry based on fusion 99mTc-macroaggregated albumin-99mTcsulfur colloid SPECT. J Nucl Med. 2013; 54: 2055-61. doi: 10.2967/jnumed.113.123257.

44. Dudeck O, Zeile M, Wybranski C, Schulmeister A, Fischbach F, Pech M, Wieners G, Ruhl R, Grosser O, Amthauer H, Ricke J. Early prediction of anticancer effects with diffusion-weighted MR imaging in patients with colorectal liver metastases following selective internal radiotherapy. Eur Radiol. 2010; 20: 2699-706. doi: 10.1007/ s00330-010-1846-z.

45. Schmeel FC, Simon B, Sabet A, Luetkens JA, Traber F, Schmeel LC, Ezziddin S, Schild HH, Hadizadeh DR. Diffusion-weighted magnetic resonance imaging predicts survival in patients with liver-predominant metastatic colorectal cancer shortly after selective internal radiation therapy. Eur Radiol. 2016. doi: 10.1007/s00330-016-44303.

46. Gulec SA, Suthar RR, Barot TC, Pennington K. The prognostic value of functional tumor volume and total lesion glycolysis in patients with colorectal cancer liver metastases undergoing $90 \mathrm{Y}$ selective internal radiation therapy plus chemotherapy. Eur J Nucl Med Mol Imaging. 2011; 38: 1289-95. doi: 10.1007/s00259-011-1758-4.

47. Ulrich G, Dudeck O, Furth C, Ruf J, Grosser OS, Adolf D, Stiebler M, Ricke J, Amthauer H. Predictive value of intratumoral $99 \mathrm{mTc}$-macroaggregated albumin uptake in patients with colorectal liver metastases scheduled for radioembolization with 90Y-microspheres. J Nucl Med. 2013; 54: 516-22. doi: 10.2967/jnumed.112.112508.

48. Fowler KJ, Maughan NM, Laforest R, Saad NE, Sharma A, Olsen J, Speirs CK, Parikh PJ. PET/MRI of Hepatic 90Y Microsphere Deposition Determines Individual Tumor Response. Cardiovasc Intervent Radiol. 2016; 39: 855-64. doi: 10.1007/s00270-015-1285-y.

49. Barabasch A, Kraemer NA, Ciritsis A, Hansen NL, Lierfeld M, Heinzel A, Trautwein C, Neumann U, Kuhl CK. Diagnostic accuracy of diffusion-weighted magnetic resonance imaging versus positron emission tomography/ computed tomography for early response assessment of liver metastases to Y90-radioembolization. Invest Radiol. 2015; 50: 409-15. doi: 10.1097/rli.0000000000000144.

50. Xing M, Lahti S, Kokabi N, Schuster DM, Camacho JC, Kim HS. 90Y Radioembolization Lung Shunt Fraction in Primary and Metastatic Liver Cancer as a Biomarker for 
Survival. Clin Nucl Med. 2016; 41: 21-7. doi: 10.1097/ rlu.0000000000000915.

51. Deipolyi AR, Iafrate AJ, Zhu AX, Ergul EA, Ganguli S, Oklu R. High lung shunt fraction in colorectal liver tumors is associated with distant metastasis and decreased survival. J Vasc Interv Radiol. 2014; 25: 1604-8. doi: 10.1016/j. jvir.2014.06.019.

52. Dunfee BL, Riaz A, Lewandowski RJ, Ibrahim S, Mulcahy MF, Ryu RK, Atassi B, Sato KT, Newman S, Omary RA, Benson A 3rd, Salem R. Yttrium-90 radioembolization for liver malignancies: prognostic factors associated with survival. J Vasc Interv Radiol. 2010; 21: 90-5. doi: 10.1016/j.jvir.2009.09.011.

53. Schonewolf CA, Patel B, Gensure RH, Narra V, Haffty BG, Nosher JL, Jabbour SK. Patterns of failure in colorectal patients with liver metastases after yttrium-90 radioembolization. Am J Clin Oncol. 2014; 37: 234-40. doi: 10.1097/COC.0b013e318277d610.

54. Tohme S, Sukato D, Nace GW, Zajko A, Amesur N, Orons P, Chalhoub D, Marsh JW, Geller DA, Tsung A. Survival and tolerability of liver radioembolization: a comparison of elderly and younger patients with metastatic colorectal cancer. HPB (Oxford). 2014; 16: 1110-6. doi: 10.1111/ hpb. 12307.

55. Abbott AM, Kim R, Hoffe SE, Arslan B, Biebel B, Choi J, El-Haddad G, Kis B, Sweeney J, Meredith KL, Almhanna K, Strosberg J, Shibata D, et al. Outcomes of Therasphere Radioembolization for Colorectal Metastases. Clin Colorectal Cancer. 2015; 14: 146-53. doi: 10.1016/j. clcc.2015.02.002.

56. Fendler WP, Ilhan H, Paprottka PM, Jakobs TF, Heinemann V, Bartenstein P, Khalaf F, Ezziddin S, Hacker M, Haug AR. Nomogram including pretherapeutic parameters for prediction of survival after SIRT of hepatic metastases from colorectal cancer. Eur Radiol. 2015; 25: 2693-700. doi: 10.1007/s00330-015-3658-7.

57. Sofocleous CT, Violari EG, Sotirchos VS, Shady W, Gonen M, Pandit-Taskar N, Petre EN, Brody LA, Alago W, Do RK, D’Angelica MI, Osborne JR, Segal NH, et al. Radioembolization as a Salvage Therapy for Heavily Pretreated Patients With Colorectal Cancer Liver Metastases: Factors That Affect Outcomes. Clin Colorectal Cancer. 2015; 14: 296-305. doi: 10.1016/j.clcc.2015.06.003.

58. Goldstein MJ, Mitchell EP. Carcinoembryonic antigen in the staging and follow-up of patients with colorectal cancer. Cancer Invest. 2005; 23: 338-51.

59. Mayer RJ, Garnick MB, Steele GD Jr, Zamcheck N. Carcinoembryonic antigen (CEA) as a monitor of chemotherapy in disseminated colorectal cancer. Cancer. 1978; 42: 1428-33.

60. Syngal S, Brand RE, Church JM, Giardiello FM, Hampel HL, Burt RW. ACG clinical guideline: Genetic testing and management of hereditary gastrointestinal cancer syndromes. Am J Gastroenterol. 2015; 110: 223-62; quiz 63. doi: 10.1038/ajg.2014.435.
61. Hampel H, Frankel WL, Martin E, Arnold M, Khanduja K, Kuebler P, Nakagawa H, Sotamaa K, Prior TW, Westman J, Panescu J, Fix D, Lockman J, et al. Screening for the Lynch syndrome (hereditary nonpolyposis colorectal cancer). N Engl J Med. 2005; 352: 1851-60. doi: 10.1056/ NEJMoa043146.

62. Gryfe R, Kim H, Hsieh ET, Aronson MD, Holowaty EJ, Bull SB, Redston M, Gallinger S. Tumor microsatellite instability and clinical outcome in young patients with colorectal cancer. N Engl J Med. 2000; 342: 69-77. doi: 10.1056/nejm200001133420201.

63. Le DT, Uram JN, Wang H, Bartlett BR, Kemberling $\mathrm{H}$, Eyring AD, Skora AD, Luber BS, Azad NS, Laheru D, Biedrzycki B, Donehower RC, Zaheer A, et al. PD-1 Blockade in Tumors with Mismatch-Repair Deficiency. New England Journal of Medicine. 2015; 372: 2509-20. doi: doi:10.1056/NEJMoa1500596.

64. Tol J, Koopman M, Cats A, Rodenburg CJ, Creemers GJ, Schrama JG, Erdkamp FL, Vos AH, van Groeningen CJ, Sinnige HA, Richel DJ, Voest EE, Dijkstra JR, et al. Chemotherapy, bevacizumab, and cetuximab in metastatic colorectal cancer. N Engl J Med. 2009; 360: 563-72. doi: 10.1056/NEJMoa0808268.

65. Sorich MJ, Wiese MD, Rowland A, Kichenadasse G, McKinnon RA, Karapetis CS. Extended RAS mutations and anti-EGFR monoclonal antibody survival benefit in metastatic colorectal cancer: a meta-analysis of randomized, controlled trials. Ann Oncol. 2015; 26: 13-21. doi: 10.1093/ annonc/mdu378.

66. Tol J, Nagtegaal ID, Punt CJ. BRAF mutation in metastatic colorectal cancer. N Engl J Med. 2009; 361: 98-9. doi: 10.1056/NEJMc0904160.

67. Ogino S, Nosho K, Irahara N, Shima K, Baba Y, Kirkner GJ, Meyerhardt JA, Fuchs CS. Prognostic significance and molecular associations of 18q loss of heterozygosity: a cohort study of microsatellite stable colorectal cancers. J Clin Oncol. 2009; 27: 4591-8. doi: 10.1200/ jco.2009.22.8858.

68. Rodrigues D, Longatto-Filho A, Martins SF. Predictive Biomarkers in Colorectal Cancer: From the Single Therapeutic Target to a Plethora of Options. BioMed Research International. 2016; 2016: 12. doi: 10.1155/2016/6896024.

69. Lopez NE, Peterson CY. Advances in Biomarkers: Going Beyond the Carcinoembryonic Antigen. Clin Colon Rectal Surg. 2016; 29: 196-204. doi: 10.1055/s-0036-1584289.

70. Mei ZB, Duan CY, Li CB, Cui L, Ogino S. Prognostic role of tumor PIK3CA mutation in colorectal cancer: a systematic review and meta-analysis. Annals of Oncology. 2016. doi: 10.1093/annonc/mdw264. 